\title{
FLOWERING IN PISUM. THREE DISTINCT PHENOTYPIC CLASSES DETERMINED BY THE INTERACTION OF A DOMINANT EARLY AND A DOMINANT LATE GENE
}

\author{
I. C. MURFET \\ Botany Department, University of Tasmania, Hobart, Australia
}

Received 20.v.70

\section{INTRODUCTION}

MENDEL (1865) found the flowering time of pea hybrids to stand almost exactly between the times of the two parents. Since that time, numerous papers have been written on the subject, including one by Rasmusson (1935) in which he called for " co-operation between genetical and physiological research". Barber (1959) used such a joint approach to the subject and the present work is part of a programme which follows his techniques, whereby physiological information is used to help detect genetic segregation and known genotypes may in turn be used in experiments to investigate the physiological action of the various genes.

Barber (1959) has proposed that late varieties differ from early varieties by possesing a dominant gene $S n$ which " has three pleiotropic effects on flowering - a delaying action and the induction of competence to respond to vernalisation and photoperiod". He suggested that the $S n$ gene causes these effects by producing a flower delaying substance (colysanthin) which must be destroyed before flowering can take place. In addition to the major control of the $S n$ locus, Barber proposed two other gene systems controlling flowering. The first is a system of genes modifying the action of the $S n$ gene. The second is a system of polygenes which alter the node of first flower by a physiological mechanism other than by way of colysanthin. Few workers have attempted an extensive array of interrelated crosses, but Rowlands (1964) has investigated flowering in diallel crosses involving seven varieties. He proposed that a simple polygenic system is primarily responsible for the control of flowering with a major gene $(S n)$ or " effective factor" which is dominant for a delay in flowering and whose effect is increased during short days. Barber recorded node of first flower and Rowlands flowering time, but the similarity between the results is even closer than Rowlands realised, for like Knavel (1967) he was under the impression that Barber had suggested the $S n$ gene operated " only by the induction of vernalisation and photoperiodic responses". It is clear from the quotation above that Barber also ascribed to $S n$ a general delaying effect.

Von Tschermak (1910), Hoshino (1915) and Wellensiek (1925a) have explanations in terms of two major genes but for reasons previously discussed by Clay (1935) these proposals are unconvincing. Most workers have only measured either flowering node or flowering time, but those who have measured both variables, report a strong correlation between the two, e.g. Tedin (1897), Wellensiek (1925a) and Rowlands (1964). Paton and Barber (1955) confirmed this correlation but found some varieties to lie well away from the regression line. Hansel (1954) paid particular attention to the rela- 
tionship between node and time. He found that although the flowering time of the $F_{2}$ plants and $F_{3}$ families was undoubtedly determined above all by the node-number, certain $\mathrm{F}_{3}$ families occurred in which the flowering time was too long or too short for their node number. In order to explain both the general high correlation of node-number and flowering time and the exceptions Hansel assumes two "Gengruppen " whose main factors are recombinable. "Gengruppe" B determines the position of the flower primordium and the rapidity of floral development and "Gen(gruppe)" $\mathrm{D}$ which modifies the speed of floral differentiation.

$\mathrm{F}_{2}$ distributions for flowering node and time have usually been continuous. However, both Oppenheim (1921) and Barber (1959) have obtained discontinuous bimodal distributions for flowering node. Tedin and Tedin (1923) also obtained one distribution which was almost discontinuous. In each case the numbers of early and late plants were consistent with a single factor difference with dominance of late. $F_{3}$ data are not given. The Tedins named the gene for high node number $S n$ and this symbol was used by Barber.

All those who have described crosses which segregated for both flowering time and the basic gene for flower colour (gene $A$ ) report a relationship between the two no matter what form the $\mathrm{F}_{2}$ distribution has taken (Lock, 1907; von Tchermak, 1910; Hoshino, 1915; Rasmusson, 1935; Hansel, 1954). White (1917) uses the symbol $L f$ for a dominant late gene linked to the $A$ locus and $L f$ is shown linked to $A$ in Lamprecht's 1961 gene-map of Pisum. Rasmusson (1935) reported that part of the variation in flowering time in the $F_{2}$ of his crosses could be explained on the segregation of a near dominant late gene $X a$ linked to $A$. He proposed that $X a$ and the le gene for internode length (or a closely linked factor) were responsible for about half the genic variation in flowering time of the $\mathrm{F}_{2}$ and that the other half was probably due to modifiers. The le gene was partially dominant for a delay in flowering time. Other workers have investigated the interaction between length factors and flowering but contradictory findings are reported for the pleiotropic effect of le on flowering. Barber (1959) presents strong evidence of a consistent cross pleiotropic effect of the flowering gene $S n$ on internode length.

Pellew (1940) found some indication of multiple alleles and more recently Wellensiek (1969) has described such a case. Marx $(1968,1969)$ has developed a system of phenotypic classification based on four photo-dependent response classes. I and G2 types both flower at a low node which is unaffected by photoperiod. However, in G2 plants, the reproductive phase is greatly prolonged in short days. $\mathrm{K}$ and $\mathrm{G}$ types are late and similar under long days and in both types flower initiation is delayed by short days. However whereas $\mathrm{K}$ plants show a limited quantitative response to short days, $\mathrm{G}$ plants show almost a qualitative response and may develop from 35 to 85 or more vegetative nodes under short days. All four types occur in crosses between G-type and I-type plants. Crosses between different I lines may give rise to $\mathrm{G} 2$ plants in $\mathrm{F}_{1}$ and a $9 \mathrm{G} 2: 7 \mathrm{I}$ ratio in $\mathrm{F}_{2}$ suggesting that two complementary genes are required to evoke a response to short days.

In the present work three qualitatively distinct types were recognised amongst twelve varieties. In addition, three further classes were distinguished on more limited quantitative differences. A crossing programme to investigate the genetic basis for differences in flowering behaviour was 
commenced in 1958 and some of these twelve varieties are first or second order derivatives of this programme. In this paper a cross is described in which two interacting major genes determine a completely discrete three-class segregation in the ratio of $4: 9: 3$.

\section{Materials, methods AND A PHENOtypic GLASSification}

\section{(a) Growing conditions}

The peas were grown in $2 \cdot 7 \mathrm{~kg}$. tin cans and plastic boxes in a $50 / 50$ by volume mixture of $6.4 \mathrm{~mm}$. dolerite chips and vermiculite. Nutrient solution in the form of a modified Hoagland's solution was supplied once a week. Our controlled environment facilities provided good control over the length of the light period but only limited control of temperature. The plants were grown on trucks $4.3 \mathrm{~m}$. long with supports for plants $2.4 \mathrm{~m}$. tall. Short day trucks moved automatically in and out of the dark compartments at prescribed times. A system of heaters and fans maintained the same temperature in the long day and short day compartments. The heaters ensured that the temperature remained high enough to eliminate the possibility of vernalisation. (Minima not less than $11^{\circ} \mathrm{C}$.) No cooling was provided apart from glasshouse vents which opened automatically at a pre-determined temperature to allow a cross-flow of outside air. (The average maximum for the hottest month in Hobart is $21^{\circ} \mathrm{C}$.) Long days were supplied by supplementing natural photoperiod with banks of incandescent and fluorescent lights. These lights could be raised or lowered and were usually adjusted to supply a meter reading of 430 lux at plant height. With this system of photoperiod control, the period of natural light received by the long day treatments varies throughout the year. Therefore, genuine photoperiod effects may be confounded with photo-dependent effects which arise from an increased level of photosynthesis.

Seeds were not sterilised and except for the first few plantings fungicidal seed dressing was not employed. Fresh vermiculite-dolerite growth-medium was used for each batch of plants. The percentage of seeds planted which survived through to harvest and scoring was normally around 98-100 per cent. The testa on seeds from mothers carrying the $A$ gene was sometimes very impervious and in one cross some seeds were found to be bullet-hard after lying for three weeks in wet growing-medium. Delayed and irregular germination is particularly to be avoided where flowering time is under consideration. Accordingly, the testa of all seeds from mothers carrying the $A$ allele were nicked with a razor blade before sowing. Prompt and regular germination followed as a result.

\section{(b) The characters recorded}

Flowering behaviour was measured in terms of two variables-flowering time (days from sowing to first open flower) and flowering node (the first node at which a flower bud is initiated, the cotyledonary node taken as zero). Data were recorded from main shoots only. Under the glasshouse conditions employed, laterals very rarely grew in long days but a lateral sometimes developed from one or two of the lower nodes under short days particularly with cooler temperatures. Plants were inspected regularly and any laterals cut off. To record flowering node, the plant was first checked to make sure 
it was a main shoot and that all basal nodes were present including the two with scale leaves. Every node from the base up was then inspected to detect the first node at which a flower had been initiated, i.e. the first node to carry a flower primordium irrespective of the degree of post-primordial development. Once the pea apex switches to producing flower primordia, it normally continues in the flowering state, but it can revert to producing vegetative buds, particularly after certain treatments (Barber, 1959; Kohler, 1965) and the sequence flowering-vegetative-flowering can result. In the present experiments all nodes above the first flower were checked for vegetative reversion.

Initiation of a flower primordium is not always followed by the growth of the primordium into a bud and the bud into a fully developed flower. The genetic analysis which follows depends in part upon this point. Flower primordia almost invariably developed into small buds but in certain genotypes the lower flower buds failed to develop into mature flowers under short days. Smooth axils without any bud were extremely rare in these crosses and possibly resulted from very early abortion of a flower primordium. Where a flower bud failed to develop into a flower it usually remained visible in the axil until harvest. If the bud itself did fall off, the thin stalk was clearly distinguishable from the squat vegetative buds which remained dormant at the non-flowering nodes.

\section{(c) The varieties}

The peas used in this work come from what some taxonomists have considered as two species-Pisum sativum and P. arvense. The taxonomy of the genus is discussed by Wellensiek (1925b) and Lamprecht (1956). All crosses were of normal fertility. Line 2 (Graue niedrige, Lamm Line 2, Rasmusson $\mathrm{Gd}$ ) is a dwarf, red flowered grey pea. Line 7 (Acacia, Lamm Line 7) is a white dwarf without tendrils. Line 8 (Lamm Line 8a) is a white cryptodwarf. Lines 2, 7 and 8 were all obtained from R. Lamm of Alnarp. Line 16 (Barton P16) is a tall red obtained from S. J. Wellensiek via D. W. Barton of Geneva, New York. Line 22 (Massey) is a dwarf, white garden pea developed from a small sample of the local commercial variety Massey. Line 24 (Greenfeast) is a dwarf white garden pea developed from local commercial stocks of Greenfeast by four generations of single plant selection. Line 53 is a dwarf white with tendrils selected from a cross between Lines 7 and 22. Line 58 is a dwarf white selected from a cross between Lines 22 and 53. Line 59 is a single plant selection direct from Line 22. Lines 60 and 61 are dwarf reds selected from a cross between Lines 2 and 53. Line 63 is a dwarf red selected from a cross between Line 53 and the maple variety Vinco.

\section{(d) Classification of the varieties into phenotypic classes}

Flowering time and flowering node data for the above varieties are given in fig. 1. Lines 22, 60 and 61 are not shown but their values are close to those of Lines 59, 8 and 53 respectively. Twelve plants of each variety were grown under long days of 18 hours and short days of 8 hours. The variance for pure varieties is usually small and was in fact zero for the flowering node of Lines 8, 58 and 60 in short days. As a result, although some points are 
fairly close together, in a statistical sense, every point on the figure differs significantly from every other point in terms of at least one co-ordinate. Biologically, there are some very marked similarities as well as differences in flowering behaviour which enable some of the varieties to be grouped together. Obvious groupings are (22, 58 and 59), (7, 8 and 60) and (2, 16, 24, 53, 61 and 63). These three groups are qualitatively distinct. There remain quantitative differences within groups and the extreme varieties 7 , 16 and 63 seem sufficiently different to warrant the formation of three

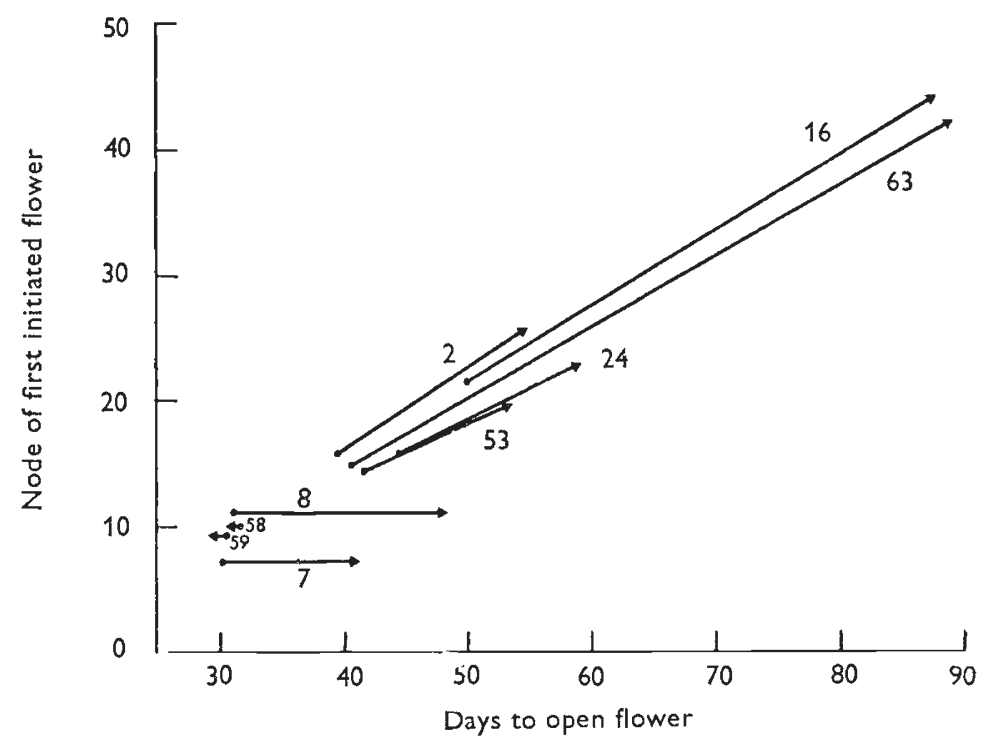

FIG. 1.-The mean node of first flower and flowering time for several varieties under short days (8 hours) and long days (18 hours). The arrow points towards the SD coordinates. The average standard errors are too small to show graphically. They are for flowering node $\mathrm{LD} \pm 0 \cdot 15$ nodes and $\mathrm{SD} \pm 0.32$ nodes and flowering time $\mathrm{LD} \pm 0.27$ days and $\mathrm{SD} \pm 0.59$ days. Data are not given for Lines 22,60 and 61 as they correspond very closely to the data for Lines 59,8 and 53 respectively. A SD photoperiod of 12 hours was used for Line 16, which was not grown at the same time as the other eleven varieties.

additional classes. Six phenotypic classes are defined below in relation to a standard variety and the comparative flowering behaviour under short and long photoperiods. Such a definition is satisfactory for classifying pure varieties but an alternative definition requiring the use of only one photoperiod is supplied where possible so that single-plant segregates may be classified. Flowering nodes given with the definitions are intended mainly as a guide, the operative part of the definition depending on a comparison of the test plant with a standard or control variety.

Early group (flowering node low (5-16) and unaffected by photoperiod)

Class ED (early developing). Flowering node and time are unaffected by photoperiod and both characters are early under short days. Examples are Lines 22, 58 and 59. Line 59 is taken as the standard variety. The first initiated flower primordium develops through to a mature flower in both photoperiods. Actually ED varieties flowered at a slightly earlier time 
under short days (Line 58 was $1 \cdot 08 \pm 0.34$ days earlier with $t_{22}=3 \cdot 21 * *$ ) but there is some doubt as to whether this effect is due to photoperiod or a slight temperature difference between the compartments. The difference of one day is relatively minute compared with the time shift of between eleven and fifty days shown by members of the other classes.

Class EI (early initiating). Flowering node is unaffected by photoperiod but flowering time is delayed by short days. Flowering node is early under long days or short days and flowering time is early under long days but late under short days. Examples are Lines 8 and 60 . Line 60 is taken as the standard variety. The late flowering time in short days results mainly from the failure of the first few flower buds to develop into mature flowers. For example, in the present experiment the first $8.92 \pm 0.78$ flower buds aborted under short days in the case of Line 8. However, even where an ED and an EI plant have their first open flower at the same node the ED plant usually flowers a week or more ahead of the EI plant. The time difference arises because the flower on the ED plant usually opens at the same time as, or before, the subtending leaf unfolds whereas the flower on the EI plant is slow developing and opens about the same time as the leaf 2 or 3 nodes above is unfolding. EI and ED plants give similar flowering data under long days. (Flowering node is usually within the range 9-16.)

Class VEI (very early initiating). These plants are similar to EI plants but differ in respect of a lower flowering node. Line 7 is taken as the standard variety. (Flowering node is usually within the range 5-8.)

Late group (flowering node high (17 or higher under short days) and influenced by photoperiod)

Class $L$ (late). In this class, both flowering time and node are delayed by short days under which photoperiod both characters are late. (Usual delay 5-15 nodes). Examples are Lines 2, 24, 53 and 61. Line 24 is taken as the standard variety. Under long days plants of class $\mathrm{L}$ are in general later than plants of classes $\mathrm{ED}$ and EI.

Class LHR (late high response). These plants have similar co-ordinates to $\mathrm{L}$ plants under long days but their flowering is very markedly delayed by short days. (Delays of 25-55 nodes with a commensurate increase in flowering time are common.) Line 63 is taken as the standard variety.

Class VL (very late). These plants have in common with LHR plants a high response to short days but differ in respect of their long day co-ordinates which are considerably later than those of L plants. (VL plants are usually 5-6 nodes later than $L$ plants under long days and rarely flower lower than node 20.) For the time being the tall Line 16 is taken as the standard variety but as these plants may attain a height of six metres under short days it seems desirable to breed a suitable dwarf to use as the standard variety. Such tall plants are not easily accommodated in our controlled environment facilities.

It is possible that some of the separations made on the basis of a limited sample of pure varieties may not be justified by crossing data and new types may be found which necessitate modification of the above scheme or recognition of further classes. However, this six-class scheme of phenotypic classification provides a framework for a study of the genetic basis of flowering differences between the twelve varieties. 


\section{Results}

The results are given here for Cross 20 which involves the ED variety Line 59 and the $\mathrm{L}$ variety Line 53 . The results may be explained by assuming a dominant late gene temporarily called $S_{2}$ and a dominant early gene $E$ which interact as follows. Genotype $e s_{2}$ is an ED. Addition of $S_{2}$ creates an $\mathrm{L}$ type. Dominant $E$ is epistatic to $S_{2}$ in terms of flowering node and $E S_{2}$ is an EI type. Gene $E$ has no effect by itself and $E s_{2}$ is an ED type.

Proposed scheme of inheritance for Cross 20:

\begin{tabular}{|c|c|c|c|c|c|}
\hline $\begin{array}{c}\text { Parents } \\
F_{1} \\
F_{2} \text { genotype }\end{array}$ & $\begin{array}{c}\text { Line } 59 \\
\text { proportion }\end{array}$ & $\begin{array}{c}E E s_{2} s_{2} \\
\text { phenotype }\end{array}$ & $\begin{array}{c}(\mathrm{ED}) \\
E e S_{2} s_{2} \\
\text { proportion }\end{array}$ & $\begin{array}{c}\text { Line 53 } \\
(\mathrm{EI}) \\
\mathbf{F}_{3} \text { phenotypes }\end{array}$ & $e e S_{2} S_{2}$ \\
\hline$E E S_{2} S_{2}$ & $1 / 16$ & EI & & EI & \\
\hline$E e S_{2} S_{2}$ & $2 / 16$ & EI & & $3 \mathrm{EI}: 1 \mathrm{~L}$ & \\
\hline$E E S_{2} s_{2}$ & $2 / 16$ & EI & $9 / 16$ & $1 \mathrm{ED}: 3 \mathrm{EI}$ & \\
\hline$E e S_{2} s_{2}$ & $4 / 16$ & EI & & $4 \mathrm{ED}: 9 \mathrm{EI}: 3 \mathrm{~L}$ & \\
\hline$e e S_{2} S_{2}$ & $1 / 16$ & $\mathrm{~L}$ & & $\mathrm{~L}$ & \\
\hline$e e S_{2} s_{2}$ & $2 / 16$ & $\mathrm{~L}$ & $8 / 16$ & $1 \mathrm{ED}: 3 \mathrm{~L}$ & \\
\hline$E E s_{2} s_{2}$ & $1 / 16$ & $\mathrm{ED}$ & & ED & \\
\hline$E e s_{2} s_{2}$ & $2 / 16$ & ED & $-4 / 16$ & ED & \\
\hline$e e s_{2} s_{2}$ & $1 / 16$ & ED & & ED & \\
\hline
\end{tabular}

\section{(a) Between-class variation}

(i) $A 4: 9: 3$ ratio. The above scheme was tested through to $\mathrm{F}_{4}$ using short day conditions. (The seed was not matured under short days; see section $3(d)$.) Flowering node distributions for the parents, $\mathrm{F}_{1}$ and $\mathrm{F}_{2}$ are shown in table 1. EI plants first appeared in $F_{1}$ and all three phenotypic classes occurred in $\mathrm{F}_{2}$ with numbers in good agreement with expectation. The discrete nature of the three classes is illustrated in fig. 2, where flowering node is plotted against flowering time for $\mathrm{F}_{3}$ plants from doubly heterozygous $\mathrm{F}_{2}$ plants. The time and node distributions are both bimodal and discontinuous. If new axes are placed parallel to the side axes and having their origin within the minimum frequency region of each distribution the three classes ED, EI and L will fall each within a single quadrant. Three quadrants permit seven different patterns ( 3 singles, 3 doubles and 1 triple). Using selfed progenies these patterns will distinguish 7 of the $9 \mathrm{~F}_{2}$ genotypes, e.g. the triple identifies $\mathrm{EeS}_{2} s_{2}$. The three ED genotypes give the same pattern and cannot be distinguished without laborious outcrossing. Progenies of fifteen seeds $\left(\frac{315}{4}=0.013\right)$ were grown from $119 \mathrm{~F}_{2}$ plants representing the entire complement of two $\mathrm{F}_{2}$ families. Genotypic numbers (table 1 lower portion) are in good agreement with expectation. Two EI plants in the $\mathrm{F}_{2}$ proved to be impenetrant $e e S_{2} s_{2}$ plants.

The observed numbers in fig. 2 differ significantly from the $4 \mathrm{ED}: 9 \mathrm{EI}$ : $3 \mathrm{~L}$ ratio $\left(\chi_{2}^{2}=8 \cdot 87^{*}\right)$ expected in an $\mathrm{F}_{3}$ derived from $\mathrm{F}_{2}$ plants of genotype $\mathrm{EeS}_{2} \mathrm{~s}_{2}$. Segregation of the $E / e$ pair, which can be followed in the presence of dominant $S_{2}$ from the comparison EI/L, is normal $\left(\chi_{1}^{2}=0.04\right)$. Segregation of the $S_{2} / s_{2}$ pair, which is obtained from the comparison $\mathrm{L}+\mathrm{EI} / \mathrm{ED}$, is significantly disturbed $\left(\chi_{1}^{2}=8 \cdot 83^{* *}\right)$. Data for progenies from $\mathrm{F}_{2}$ plants of 
× $>11$ |

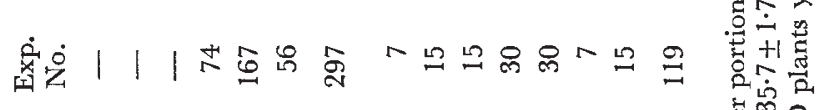

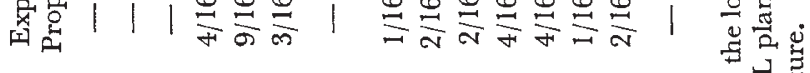

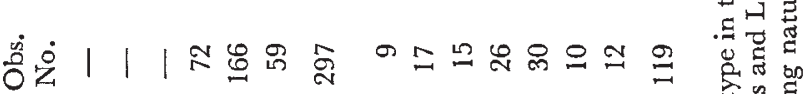
\& | | | | | r a | | | | | | | | | |

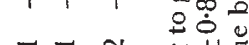
争 总 若

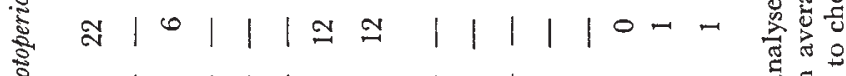

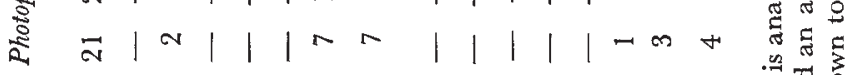

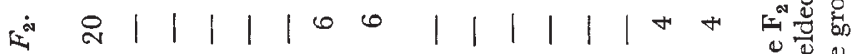
章 $911|1| 1^{+*}|1| 1|1| 100$

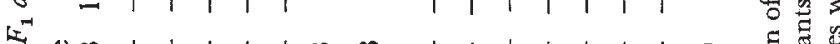

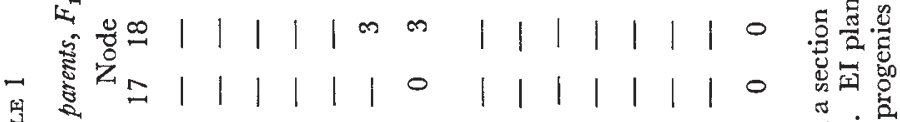
要

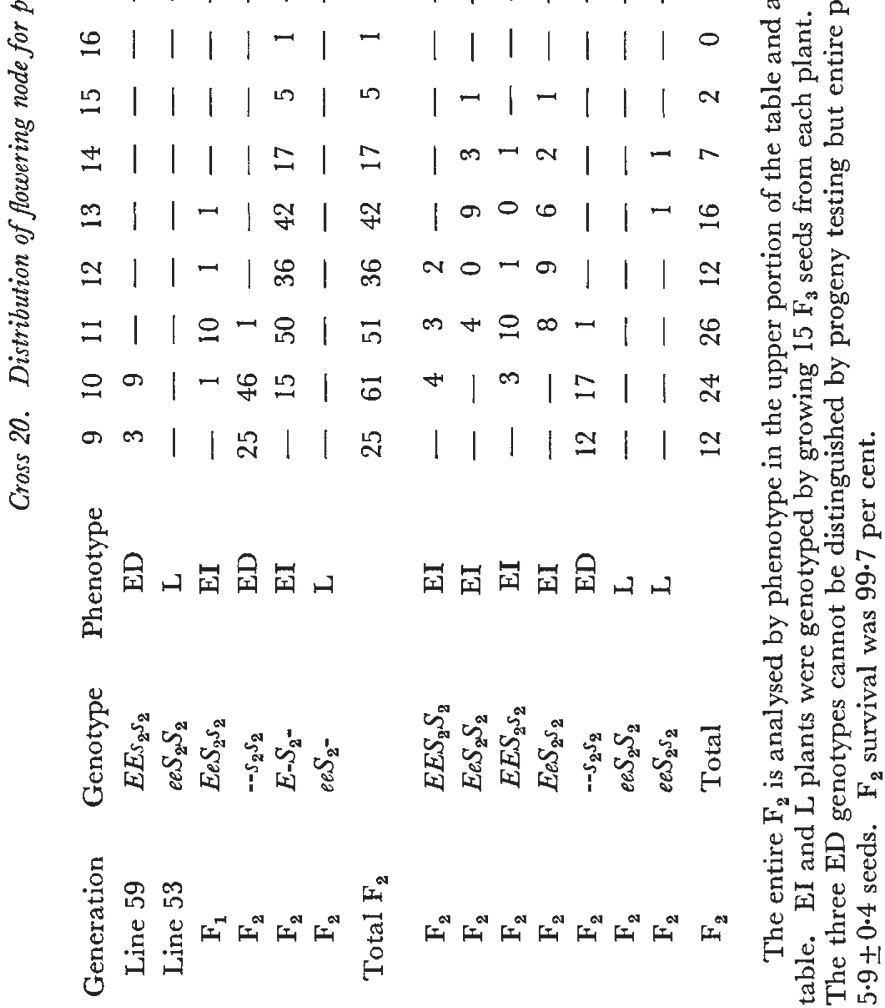


genotypes $E e S_{2} S_{2}$ and $E E S_{2} s_{2}$ are given in table 2. Flowering node and flowering time distributions are again discontinuous with minimum gaps of 4 nodes and 14 days respectively. The observed numbers are in good agreement with expectation. Progenies from $\mathrm{F}_{2}$ plants of genotype ee $S_{2} s_{2}$ included $4 \mathrm{EI}$ plants. The expected ratio is $1 \mathrm{ED}: 3 \mathrm{~L} . \mathrm{F}_{4}$ data (lower part of table 2) revealed these EI plants as impenetrant $\mathrm{L}$ plants. The adjusted

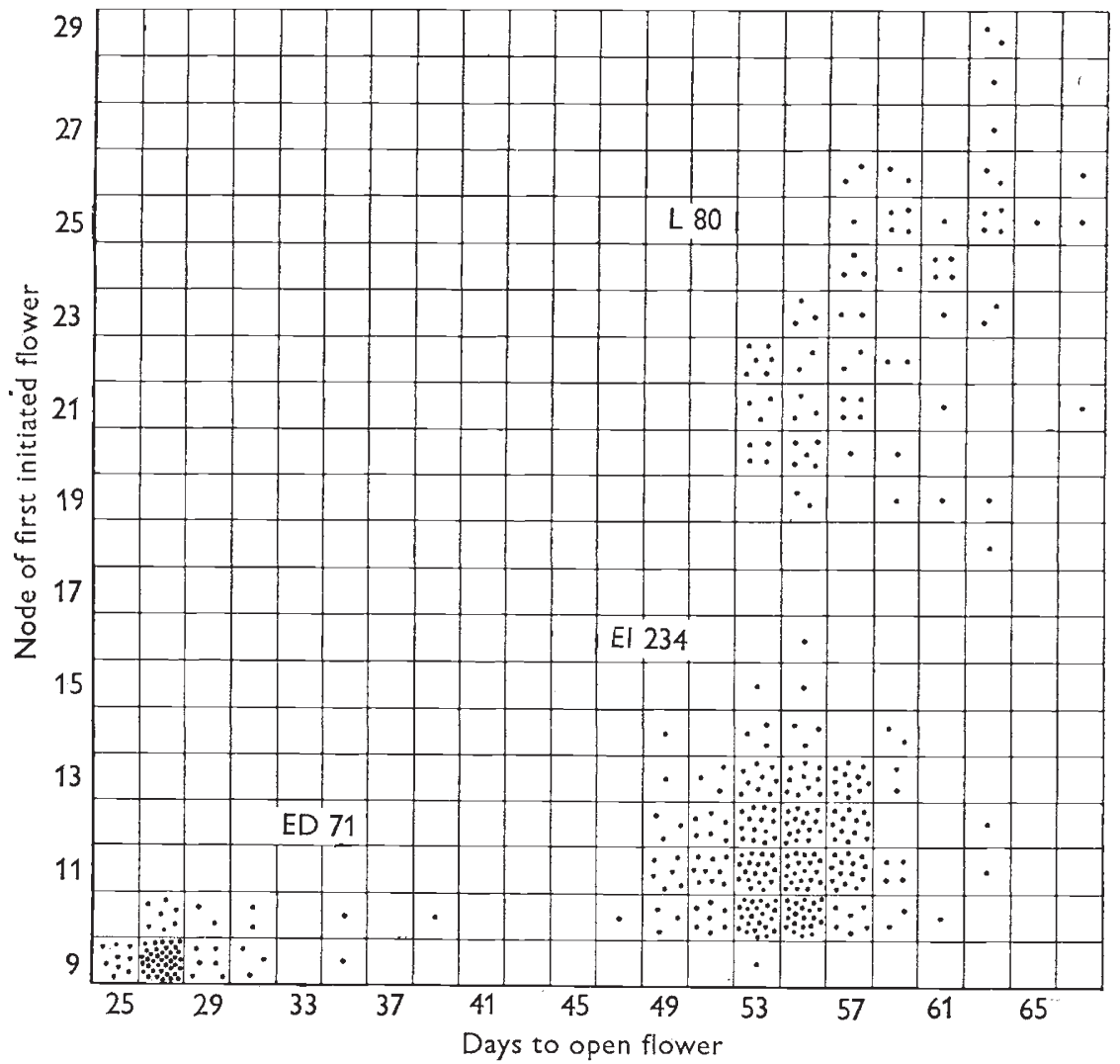

FIG. 2.-Each dot represents the flowering node and flowering time for a single plant in the $\mathrm{F}_{3}$ descended from $\mathrm{F}_{2}$ plants of genotype $E e S_{2} s_{2}$ in Cross 20. The plants were grown under an 8 hour photoperiod. The expected numbers are ED (genotype $--s_{2} s_{2}$ ) 96, EI $\left(E-S_{2^{-}}\right) 217$ and L $\left(e e S_{2^{-}}\right) 72 . \quad \chi_{2}^{2}=8 \cdot 87^{*}$. The disturbed segregation results from a shortage of recessive $s_{2}$ plants. $* \mathrm{P}<0.05, * * \mathrm{P}<0.01$ and $* * * \mathrm{P}<0.001$.

segregation data are in good agreement with expectation. All ED segregates bred true in $\mathrm{F}_{4}$.

(ii) Disturbed segregation for gene $\mathrm{S}_{2}$. The total observed segregation for the $E / e$ pair of $566 / 189$ is almost an exact $3: 1$. The total observed segregation for the $S_{2} / s_{2}$ pair of $818 / 224$ shows a significant disturbance $\left(\chi_{1}^{2}=\right.$ $\left.6 \cdot 82^{* *}\right)$. This tendency towards a deficiency of recessives has been confirmed in subsequent crosses.

(iii) Penetrance of $\mathrm{S}_{2}$. Altogether a total of 137 plants of genotype ee $S_{2}$ were checked out by progeny testing. Six of these plants were phenotypically EI. These plants are termed impenetrant $\mathrm{L}$ plants because the two classes EI and L are fully discrete and the majority of $e e S_{2}$ - plants have 


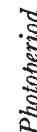

$x$
$x$

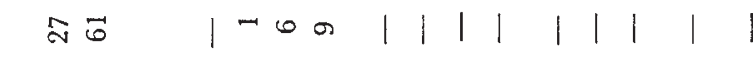

요 $\left.\quad\right|^{\infty}=1||^{+}=\left.1\right|^{-1} \mid 1$

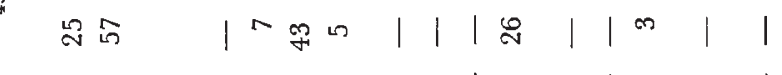

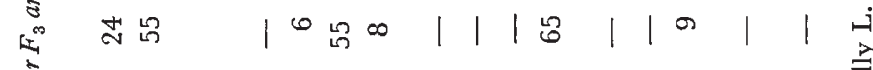

这茎

छัँ ลี

ह

여 $|\wedge||||||||\vec{a}|$ ก

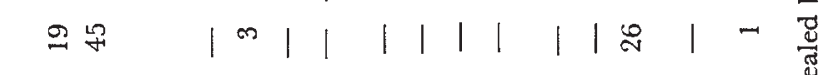

蛋

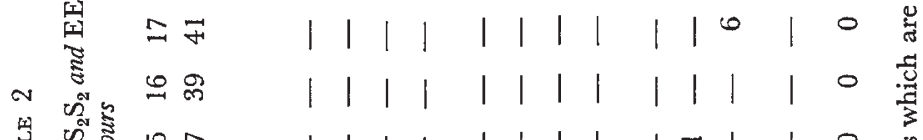

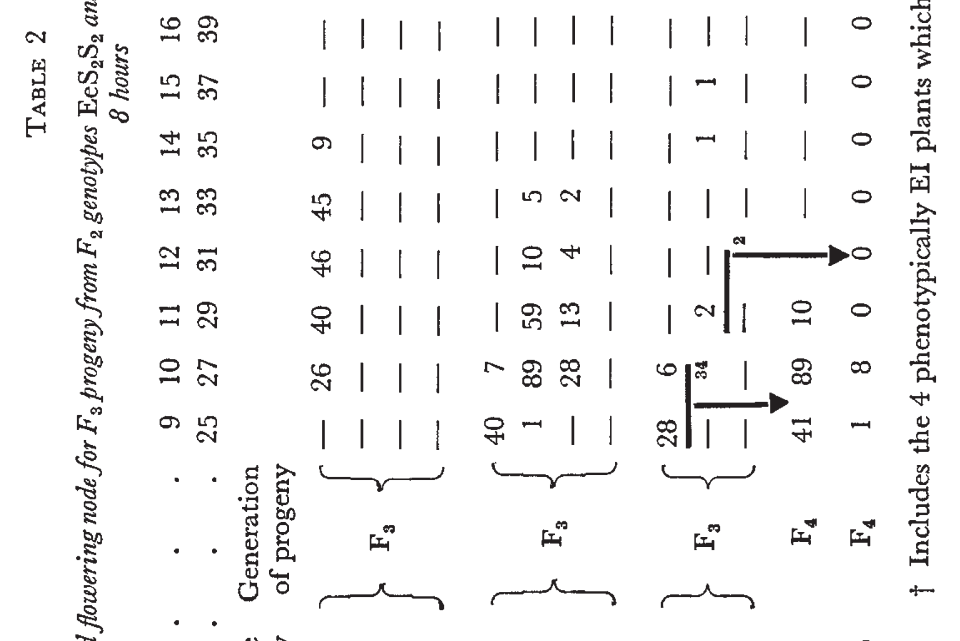

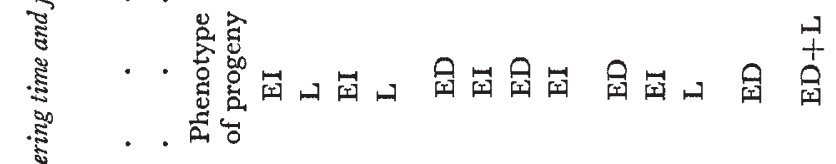

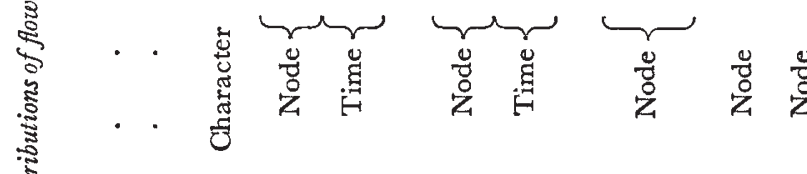

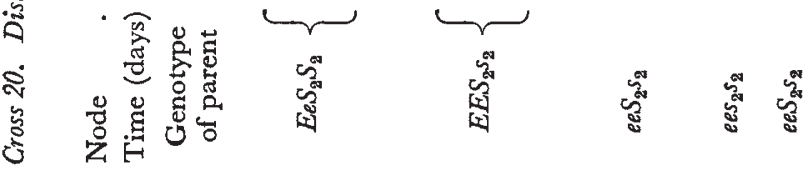


phenotype L. $S_{2}$ is fully penetrant in terms of flowering time but apparently has a tendency towards incomplete penetrance in terms of flowering node. This tendency has also been confirmed in subsequent crosses.

\section{(b) Within-class variation}

The genetic contribution to within-class variation may well contain both polygenic and major gene components. Cross 20 provides little evidence on the polygenic component although transgression by the $\mathrm{L}$ class in the $F_{2}$ suggests the existence of a quantitative system. In table 1 the $L$ parent has a range of three nodes and the $\mathrm{L}$ segregates a range of nine nodes. However, there is very definite evidence that within-class variation is substantially influenced by new combinations and dosages of the major genes.

(i) Flowering node. Considering flowering node the range for the early class expanded from 2 nodes for the parent to 8 nodes for the $\mathrm{F}_{2}$ (see table 1 ). This increase comes largely from the appearance of a new combination of major genes, namely, $E-S_{2^{-}}$. This genotype creates a class of EI plants different from either parent but when only flowering node is considered, ED and EI plants constitute a single class. ED plants flower at a lower node on the average than EI plants. Even the earliest EI sub-group (table 1, genotype $E E S_{2} S_{2}$ ) is significantly later than the ED plants (difference $1 \cdot 14$ \pm 0.30 nodes, $t_{37}=3.88^{* * *}$ ). The dominant gene $S_{2}$ therefore causes a slight increase in flowering node even in the presence of dominant $E$. In contrast it seems likely from the close similarity between the flowering node of Line 59 (genotype $E E s_{2} s_{2}$, mean $9 \cdot 75 \pm 0 \cdot 13$ nodes) and the flowering node of the ED segregates (genotypes $E-s_{2} s_{2}$ and $e e s_{2} s_{2}$, mean $9 \cdot 63 \pm 0 \cdot 10$ nodes) that dominant $E$ on its own has no effect. Proof of this point would involve laborious genotyping of ED plants.

Within the EI group gene $E$ shows a dosage effect which is revealed by the comparisons $E E S_{2} S_{2} / E e S_{2} S_{2}$ (difference $2 \cdot 04 \pm 0 \cdot 40$ nodes, $t_{24}=5 \cdot 10^{* * *}$ ) and $E E S_{2} s_{2} / E e S_{2} s_{2}$ (difference $1 \cdot 12 \pm 0.33$ nodes, $t_{39}=3 \cdot 41^{* *}$ ). Two doses of the $E$ allele caused flowering at a lower node than one dose in the presence of either one or two doses of $S_{2}$. On the other hand gene $S_{2}$ shows no dosage effect in the EI group as seen from the comparisons $E E S_{2} S_{2} / E E S_{2} s_{2}$ (difference $0.29 \pm 0.37$ nodes, $t_{22}=0.78$ ) and $E e S_{2} S_{2} / E e S_{2} s_{2}$ (difference $0.63 \pm 0.36$ nodes, $\left.t_{41}=1 \cdot 75\right)$. However, gene $S_{2}$ did show a dosage effect in the $\mathrm{L}$ class as shown by the comparison $e e S_{2} S_{2} / e e S_{2} S_{2}$ (difference $2 \cdot 10 \pm 0.62$ nodes, $t_{18}=3 \cdot 39 * *$; impenetrant plants excluded).

(ii) Flowering time. EI and L plants form a single class in terms of flowering time but gene combination $E-S_{2^{-}}$flowers on the average a little earlier than $e e S_{2^{-}}$. In fig. 2, EI plants flower $3.87 \pm 0.45$ days earlier than $\mathrm{L}$ plants $\left(t_{312}=8 \cdot 54^{* * *}\right)$. The third and fourth rows of table 2 illustrate the same phenomenon. The delaying effect which dominant $S_{2}$ exerts on flowering time is therefore slightly reduced in short days by the presence of dominant $E$. Under long days of course EI plants are substantially earlier than L plants (see fig. 1).

\section{(c) Pleiotropic effects of the $\mathrm{S}_{2}$ gene}

Gene $E$ seems mainly concerned with the regulation of flowering node and appears to have no effect in the absence of $S_{2}$. In contrast gene $S_{2}$ has 
several effects. (i) By itself $S_{2}$ causes an increase in both flowering node and flowering time. Addition of gene $E$ nullifies the effect on flowering node but a substantial delay in flowering time is still manifest under short days. (ii) Gene $S_{2}$ confers the ability to respond to photoperiod in terms of both node and time but the ability to respond in terms of flowering node is not manifest in the presence of $E$. (iii) Gene $S_{2}$ causes a substantial (400600 per cent.) increase in plant height. This increase derives largely from an increase in the total number of internodes. (That is not to say $S_{2}$ has no effect on internode length but this question is not dealt with here.) The increased number of internodes in turn derives from firstly an increase in the number of vegetative nodes in $e S_{2}$ plants or reproductively ineffective nodes in $E S_{2}$ plants where the lower flower buds abort in short days and secondly from a prolongation of growth after seed-set has commenced. ED plants, which lack $S_{2}$, have a marked tendency to complete their life-cycle rapidly. Under our glasshouse short day conditions the first flower develops and usually sets seed whereupon further apical growth promptly ceases. It follows from the above remarks that (iv) gene $S_{2}$ causes a substantial (300-600 per cent.) increase in yield. In the $\mathrm{F}_{2}$ of Cross 20 the lowest yield amongst the L segregates was 24 seeds and the highest yield for an ED segregate was 11 seeds. (For mean yield see footnote to table 1.)

In general gene $S_{2}$ opposes the onset of flowering and senescence.

\section{(d) Distinguishing the classes, ED, EI and L}

The formal definition of classes ED, EI and L calls for the recording of flowering node and flowering time under short days. The discreteness of the classes in terms of these criteria has already been discussed with reference to fig. 2. In fact the three classes were so obviously distinct in Cross 20 that they were virtually distinguishable at a glance. At maturity ED plants were very conspicuous on account of their small size and low yield. (The distinctness of the ED segregates was also apparently obvious to the local mice, which, during a short-lived spell of marauding, had eaten exclusively of their seed. The data given here are, however, not biased on that account.) The conspicuous difference between the EI and L plants was the presence of small undeveloped flower buds in EI plants at nodes which were vegetative in L plants. In fig. 2, three plants flower at a slightly later time than the main ED group. These plants are closest to the ED group on formal criteria and their ED nature was confirmed visually. The slightly later flowering time of these plants was caused by abortion of the first flower buds. This may happen to ED plants under short days if light conditions are poor but even under these conditions the buds usually develop to a greater extent than the lower flower buds of EI plants.

From the foregoing remarks it is clear that certain economies of labour, time and space may be effected. Visual identification of ED and EI plants along the lines just described saves the labour of recording flowering time. These classes were visually distinguished in the $\mathrm{F}_{2}$ of Cross 20 and no error in identification was found in the 97 plants checked out in $F_{3}$ using formal criteria. Also in practice sufficient separation between the three classes was obtained by holding the plants in short days only until the 15th and 16th leaf unfolded and then transferring the plants to natural photoperiod or natural plus supplementary light. (Small samples were taken through to 
open flower in short days to check on extreme segregants.) In this way short day space was freed and experimental time saved by providing conditions more favourable for seed-set and maturation.

\section{Discussion}

A discussion of the possible action of genes $E$ and $S_{2}$ and the relationship of these genes to previously described genes would be relevant at this point. However these matters are more conveniently dealt with in the discussion of a following paper in which the results of several further crosses are introduced.

Concerning the phenotypic classifications described here and by Marx (1968, 1969) it may seem that classes ED, EI, L and LHR correspond respectively to classes I, G2, K and G. Short day treatment was seldom continued in the present experiments beyond the time of open flower but small samples of the EI variety Line 60 and the L variety Line 53 were tested in this way and both types showed a prolonged reproductive phase when maintained under short days. This contrasts with the short reproductive phase reported for $\mathrm{K}$ plants. Again the flowering node of 42 under an 8 hour photoperiod reported here for the LHR Line 63 (fig. 1) hardly matches the almost qualitative response to short days reported for $\mathrm{G}$ plants. However, in one experiment an LHR plant attained 71 vegetative nodes under short days. (Their ability to respond to photoperiod seems to be substantially influenced by temperature being greater under warm conditions.) Finally, classes ED and EI seem equivalent to classes I and G2 respectively from the totality of features characteristic of each class although the EI variety Line 60 seems to have only about half the G2 capacity for a prolonged reproductive phase under short days. (Perhaps this difference is due to different growing conditions.) In addition, emphasis is placed on different distinguishing criteria-namely delayed flowering time in short days for EI plants and extended reproductive phase in short days for G2 plants. A type satisfying the second but not the first condition would classify ED and G2 using only these criteria. Of course, it may require a new class in either system if it differed sufficiently from the usual G2 plants or the standard ED variety.

The above remarks cast doubt on the equivalence of at least some of the classes and illustrate the difficulties of defining a class on phenotype alone. Tying the class definition to a standard variety bases the definition on the reactions of a pure genotype and provides a reference point which accommodates uncontrolled variation between experiments. Again for physiological work it is the genotype which is of key importance and a pool of standard genotyped varieties would be very useful in this respect.

\section{Summary}

1. The flowering behaviour of twelve pea varieties was studied under short and long photoperiods. Six phenotypic classes were recognised and defined in relation to the behaviour of six standard varieties.

2. A start was made on the genetic analysis of these flowering differences. A cross between an L (late) variety and an ED (early developing) variety gave an EI (early initiating) $\mathrm{F}_{1}$ and a ratio of $4 \mathrm{ED}: 9 \mathrm{EI}: 3 \mathrm{~L}$ in $\mathrm{F}_{2}$, all classes being fully discrete. 
3. Considering node of first initiated flower and time of open flower, under short days ED plants are early in node and time, EI plants are early in node but late in time and L plants are late in node and time.

4. These results were explained by assuming two dominant genes $S_{2}$ and $E$ which interact as follows. Genotype $e s_{2}$ is ED. $S_{2}$ by itself gives an L type. $E$ is epistatic to $S_{2}$ in terms of flowering node but by itself has no effect so that $E S_{2}$ is EI and $E s_{2}$ is ED. This theory was confirmed by growing $\mathrm{F}_{3}$ and some $\mathrm{F}_{4}$.

5. Major genes $E$ and $S_{2}$, by dosage and combination effects, also contribute substantially to within-class variation.

6 . The $E / e$ pair segregate normally but the $S_{2} / s_{2}$ pair show disturbed segregation with a slight deficiency of recessives.

7. $S_{2}$ is sometimes impenetrant in terms of flowering node.

8. $S_{2}$ has pleiotropic effects on flower initiation, floral development, ability to respond to photoperiod, senescence, height and yield.

Acknowledgments.-I wish to thank Professor H. N. Barber, F.R.S., for developing and encouraging my interest in a joint physiological-genetic approach to the control of flowering, Professor W. D. Jackson and Mr C. Pearson for the design and construction of the controlled environment facilities and the Rural Gredits Development Fund of the Reserve Bank of Australia for a grant towards these facilities.

\section{REFERENCES}

Barber, H. N. 1959. Physiological genetics of Pisum. II. The genetics of photoperiodism and vernalisation. Heredity, 13, 33-60.

GLAY, s. 1935. Notes on the inheritance of quantitative characters in a cross between two varieties of garden pea (P. sativum). F. Pomol. and Hort. Sci., 13, 149-189.

HÄNSEL, H. 1954. Versuche zur Vererbung der Nodienzahl-Blühzeit-Relation im langen Tag bei Erbsensorten. (Pisum sativum $\times$ Pisum sativum ssp. arvense.) Der Züchter, 24, 97-115.

Hoshino, y. 1915. On the inheritance of the flowering-time in peas and rice. 7. Coll. Agr. Hokkaido Imp. Univ., Sapporo, 6, 229-288.

KNAVEL, D. E. 1967. A daylength-sensitive, tall-mutant pea. 7. of Heredity, 58, 78-80.

KöHler, G. D. 1965. Die Physiologie der Blütenbildung bei Pisum sativum. Z. Pfanzenphysiol., 53, 429-451.

LAmprecht, H. 1956. Pisum sativum L. oder $P$. arvense L. Eine nomenklatorische Studie auf genetischer Basis. Agri Hort. Genet., 14, 1-4.

lampreght, H. 1961. Die Genenkarte von Pisum. Agri Hort. Genet., 19, 360-401.

LOCK, R. H. 1907. The present state of knowledge of heredity in Pisum. Ann. Roy. Bot. Gard. Peradenyia, 4, 93-111.

MARX, G. A. 1968. Influence of genotype and environment on senescence in peas Pisum sativum L. Bio. Science, 18, 505-506.

marx, G. A. 1969. Some photo-dependent responses in Pisum. I. Physiological behavior. Crop Sci., 9, 273-276.

MENDEL, G. 1865. Versuche über Pflanzenhybriden. Verhand. Naìurf. Ver. Brunn, 4, 3-47. (English transl.)

oppenheim, J. D. 1921. De erfelijkheid van het vroeg of laat bloeien bij Erwten. Ver. $t$. Bev. van Wetensch. Teelt, Ber. a. d. Leden No. 10, 2-5. (Citation from Bot. Abst. \& Wellensiek (1925b).)

PATON, D. M., AND BARber, H. N. 1955. Physiological genetics of Pisum. I. Grafting experiments between early and late varieties. Aust. 7. biol. Sci., 8, 231-240.

PEllew, G. 1940. Genetical studies on the first reciprocal translocation found in Pisum sativum. 7. Genet., 39, 363-390.

Rasmusson, J. 1935. Studies on the inheritance of quantitative characters in Pisum. I. Preliminary note on the genetics of time of flowering. Hereditas, 20, 161-180.

Rowlands, D. G. 1964. Genetic control of flowering in Pisum sativum L. Genetica, 35, 75-94. 
TEDIN, H. 1897. Några synpunkter vid förädling av ärter. Sveriges Utsädes föris Tidskrift, 7, 111.

TEDin, H., AND tedin, o. 1923. Contributions to the genetics of Pisum. III. Internode length, stem thickness and place of the first flower. Hereditas, 4, 351-362.

Tschermak, E. von. 1910. Ueber die Vererbung der Blütezeit bei Erbsen. Verh. Naturf. Ver. Brunn, 49, 169-191.

Wellensiek, s. J. 1925a. Pisum-crosses. I. Genetica, 2, 1-64.

Wellensiek, s. J. 1925b. Genetic monograph on Pisum. Bibliog. Genet., 2, 343-476.

wellensiek, s. J. 1969. The physiological effects of flower forming genes in peas. $Z$. $P f$. Physiol., 5, 388-402.

WHITE, O. E. 1917. Studies of inheritance in Pisum. II. The present state of knowledge of heredity and variation in peas. Proc. Amer. Phil. Soc., 56, 487-589. 